\title{
Biyodizel Karışımları ile Çalışan Bir Dizel Motorunda Performans, NO ve İs Emisyonlarını Etkileyen Faktör Seviyelerinin Taguchi Yöntemi ile Belirlenmesi
}

\author{
*11Aslan Çoban \\ ${ }^{1}$ Sakarya Uygulamalı Bilimler Üniversitesi, Teknoloji Fakültesi, Makina Mühendisliği Bölümü, Serdivan, Sakarya, \\ acoban@subu.edu.tr,
}

Araştırma Makalesi

Geliş Tarihi: 26.10 .2020

Kabul Tarihi: 14.03.2021

$\ddot{O} \mathbf{z}$

Dizel motorlarının çalışma prensibi gereği buji ateşlemeli motorlara göre sahip oldukları üstünlüklerinin yanında, NO ve is emisyonları açısından büyük dezavantajları vardır. Yakıt sarfiyatlarının düşük olması, birçok uygulamada yaygın olarak kullanılmasına neden olmaktadır. Yürürlüğe giren yasal düzenlemelerin sağlanması için birçok ülkede dizel yakıtlarına belirli oranlarda biyodizel karıştırılma zorunluluğu vardır. Biyodizel, dizel motorlarında yaygın olarak kullanılan yenilenebilir, alternatif yakıtların başında gelmektedir. Bitkisel ve hayvansal yağlardan elde edilen biyodizel, oksijen içeriğine sahip düşük emisyon profilli bir yakıttır. Bu çalışmada, direkt enjeksiyonlu bir dizel motorunda, farklı oranlarda biyodizel karışımlarının optimum oranları motor performans parametreleri, NO ve is emisyonları açısından en uygun çalışma şartları Taguchi yöntemi kullanılarak belirlenmiştir. Belirlenen faktör ve seviyelerine göre deney tasarımı yapılmıştır. L9 ortogonal dizin seçiliştir. Çalışma sonucunda, motor performans parametreleri, NO ve is emisyonları açısından en uygun faktör seviyeleri Taguchi yöntemi ile belirlenmiştir. Faktörlerin etki dereceleri ANOVA analizi ile test edilmiştir.

Anahtar Kelimeler: Taguchi metodu, Biyodizel karışımları, NO emisyonu, İs emisyonu

\section{Determination of the Factors Levels Affecting Performance, NO and Soot Emissions in a Diesel Engine Operating Biodiesel with Taguchi Method}

\footnotetext{
${ }^{* 1}$ Sakarya University of Applied Sciences, Faculty of Technology, Department of Mechanical Engineering, Serdivan, Sakarya acoban@subu.edu.tr
}

\begin{abstract}
Although the diesel engines have superior features according to the spark ignited engines, they have disadvantages in terms of NO and black carbon emissions. Nevertheless, they are used in many applications because of their low fuel consumption features. Determined rates of biodiesel fuel mixture to the diesel fuels is forced in many countries due to the effectuated legal regulations. Biodiesel is one of the commonly used renewable and alternative fuels in diesel engines. Biodiesels are obtained from vegetable and animal oils having low emission profile including oxygen. In this study, the optimum operating conditions in terms of engine performance parameters, NO and soot emissions of biodiesel mixtures in different proportions in a direct injection diesel engine are determined through optimization using the Taguchi method. Experimental design is made according to the determined factors and levels. L9 orthogonal array is selected. As a result of the study, the most suitable factor levels in terms of engine performance parameters, NO and soot emissions are stated by Taguchi method. The factors' degrees of influence are tested by ANOVA analysis.
\end{abstract}

Keywords: Taguchi method, Biodiesel mixture, NO emissions, Smoke emissions 


\section{GíRiş}

Dünya üzerinde birincil enerji kaynaklarının başında fosil yakıtlar gelmektedir. Ancak yapılan araştırmalarda mevcut kaynakların her geçen gün azaldığı vurgulanmaktadır [1]. Ayrıca, fosil yakıtların kullanımı sonucunda hava kirliliği ve küresel ısınmaya neden olan zararlı emisyonlar yüksek oranda atmosfere salınmaktadır. Bundan dolayı hem fosil yakıtlara bağımlılı̆̆ı azaltacak hem de emisyon miktarlarını azaltacak, yenilenebilir, alternatif yakıtların kullanımı her geçen gün artmaktadır [2]. Dizel motorlarında kullanılan alternatif yakıtların başında biyodizel gelmektedir [3]. Biyodizel motorin ile yanma sonu emisyonları açısından karşılaştırıldığında; daha düşük karbon monoksit, partikül emisyonu ve yanmamış hidrokarbonlara sahiptir [4-6]. Biyodizelin dizel yakıtına göre oksijen içeriğinin fazla olması daha iyi yanma karakteristikleri gösterdiğinden dolayı daha düşük is emisyonlarını dışarıya salmaktadır. Biyodizelin bu avantajları nedeniyle birçok araştırmacı tarafindan farklı bitkisel veya hayvansal yağlardan elde edilen biyodizel, motorlarda araştırma konusu olmuştur $[7,8]$.

Literatüre bakıldığında; bitkisel veya hayvansal yağlardan elde edilmiş biyodizel-dizel karışımları, dizel motorlarında yakıt olarak kullanılması durumunda, motor torkunun ve efektif gücün arttığı görülmektedir. Bazı araştırmacılar \%20 biyodizel karışımı kullanımında motor torkunda meydana gelen artmanın daha yüksek olduğunu tespit etmişlerdir [913]. Ayhan ve ark. [14] Ayçiçek yağından transesterifikasyon yöntemiyle elde etikleri metil ester-dizel karışımlarının motor performans ve egzoz emisyonları üzerine etkilerini deneysel olarak incelemişlerdir. Deneylerde üç karışım yakıtı (B10, B20 ve B50) kullanmışlardır. Deneysel çalışma sonucunda B10ve B20 yakıtlarında güç ve torkta artmalar olurken, B50 karışımında azalmalar tespit etmişlerdir. Optimum maksimum artmayı B20 yakıtında tespit etmişlerdir. Ayrıca, B20 karışım oranında $\mathrm{HC}, \mathrm{CO}$ ve is emisyonları azalırken, NO emisyonları artmıştır. Cesur ve ark.[15], tavuk yağından transesterifikasyon yöntemi ile elde ettikleri yakıtı farklı oranlarda (B10, B20 ve B50) dizel yakıt ile karıştırmışlardır. Motor deneylerini tek silindir ve DI bir dizel motorunda gerçekleştirmişlerdir. Deneysel çalışma sonucunda; B10 ve B20 yakıtlarında standart dizele göre motor performans parametrelerinde iyileşmelerin meydana geldiğini, B50 de ise bir miktar kötüleşmelerin olduğunu tespit etmişlerdir. Ayrıca tüm karışım oranları için NOx emisyolarında dikkate değer kötüleşmeler tespit etmişlerdir.

Y1lmaz [16], direkt enjeksiyonlu bir dizel motorunda yakıt olarak \% 10 balık yağı biyodizel ve \% 90 dizel yakıt karışımları kullanmıştır. Deneysel çalışmada motor devri 2200 ve 4 farklı yük konumunda deneyleri gerçekleştirmiştir. Deneysel çalışma sonucunda balık yağı biyodizelin alt 1sıl değeri dizel yakıtına göre daha düşük olması sebebiyle performansta bir miktar kötüleşme olduğunu saptamıştır. Uyumaz ve ark. [17], direkt enjeksiyonlu bir dizel motorda atık zeytinyağından elde ettikleri biyodizelin motor performans ve egzoz emisyonları üzerine etkilerini deneysel olarak incelemişlerdir. Motor deneylerini tek devir ve beş farklı motor yükünde gerçekleştirmişlerdir. Deneysel çalışma sonucunda, motor torkunda azalma, NOx emisyonlarında ise artmalar saptamışlardır. Sarıdemir [18], bitkisel yağlardan elde ettiği biyodizelin motorda yakıt olarak kullanılmasının egzoz emisyonları üzerine etkilerini deneysel olarak incelemiştir. Deneysel çalışma sonucunda, biyodizel karışımlı yakıtların motorda kullanıldığında $\mathrm{CO}, \mathrm{CO} 2, \mathrm{HC}$ ve gürültü emisyonlarının azaldığını fakat NOx emisyonlarında ise artmalar olduğunu saptamıştır.

İçten yanmalı motorlarda kullanılan petrol kökenli yakıtların sınırlı olması ve emisyon oranlarının yüksek olması, araştırmacıları alternatif yakıtlar konusunda araştırmaya teşvik etmektedir. Biyodizel yakıtlar, dizel motorlar için bitkisel yağlardan üretilen önemli bir yenilenebilir alternatif yakıttır. Biyodizel, dizel yakıtı ile karıştırılabildiği gibi, saf olarak da dizel motorda kullanılabilmektedir. Bu çalışmada, atık bitkisel yağlardan üretilen biyodizel ve standart dizel yakıt karışımlarının tek silindirli bir motorun egzoz ve gürültü emisyonlarına olan etkisi incelenmiştir. Yakıt karışımları içeriğindeki biyodizelin $\mathrm{CO}, \mathrm{CO} 2, \mathrm{HC}$ ve gürültü emisyonlarını azalttığı, NOx emisyonunu ise artırdığı görülmüştür.

Dizel motorlarının buji ateşlemeli motorlara göre en büyük avantajı sıkıştırma oranının yüksek olması ve çok daha fakir karışımlar ile çalışabilmesidir. Fakir karşımla çalışabilmeleri nedeniyle düşük kısmi yanma ürünü salmaktır. Ancak, sıkıştırma oranı ve yüksek hava fazlalık katsayısı ile çalışmalarından dolayı çok daha yüksek oranda NO emisyonu açığa çıkarmaktadır. Aynı zamanda heterojen karışım teşkili nedeniyle is emisyonlarının miktarı buji ateşlemeli motorlara göre fazladır[19,20]. NOx emisyonlarının oluşma nedeni; silindir içi yüksek sıcaklık, reaksiyona giren hava miktarı ve reaksiyon süresidir. İs emisyonları ise silindir içerisinde oksijen konsatrasyonuna bağlı olarak değişmektedir. Dizel motorlarında, biyodizel kullanıldığında bazı çalışmalarda NOx emisyonlarının arttığı, bazılarında ise azaldığı vurgulanmaktadır. Çalışmalardaki bu farklılıklar, motor ayar parametrelerinden, biyodizelin elde edildiği yağ ve elde edilme yönteminden kaynaklı olmakla birlikte; motor çalışma şartları (motor devir ve yükü) ve yakıt içerisinde bulunan biyodizel karışım oranına göre de değişmektedir. Dolayısıyla karışım oranı ve motor çalışma şartlarının motor performans ve emisyon karakteristikleri açısından optimizasyonu önem arz etmektedir. Literatürde dizel motorlarında biyodizel kullanıldığında deneyler esnasında motor yükünün sabit veya devir sayısının sabit tutulduğu pek çok çalışma mevcuttur [21,22]. Dizel biyodizel karışımları ve motor yüklerine göre yapılan çalışmalar literatürde oldukça azdır. Bu deneylerin tüm parametrelerin denenmesi ve kombinasyonlara göre deneylerin tekrarlanması hem uzun zaman almakta hem de deney maliyetlerini arttırmaktadır. Bundan dolayı, tam faktör deney tasarımları yerine kısmi faktöriyel deney tasarım 
yöntemlerinin kullanılması uygun olmaktadır. Kısmi faktöriyel deney tasarımı; tam faktöriyel deney tasarımındaki maliyet ve zamandan tasarruf sağlamaya yönelik olarak geliştirilmiş deney tasarım yöntemleridir. Taguchi yöntemi birçok alanda kullanılan kısmi faktöriyel deney tasarım yöntemlerinin başında gelmektedir. Bu yöntem standart deney tasarım yöntemlerinin bir kombinasyonudur ve iki amacı vardır. Bunlar; 1) Kalite değişkenini hedefe olabildiğince yaklaştırmak, 2) Varyansı minimum yapmaktır. Taguchi yönteminde, deneysel çalışmalarda dikkate alınan tüm faktör ve seviyelerinin her bir kombinasyonlarının denenmesi yerine Taguchi tarafından önerilen standart ortogonal dizilerin oluşturduğu kombinasyonlara göre deneyler yapılmaktadır. Elde edilen deney kombinasyonlarına göre yapılan deney gözlem değerlerinin, hedef değere göre belirlenmesinde farklı yöntemler kullanılmaktadır. Deney sonuçları arasındaki farklılığı minimum yapmak için $\mathrm{S} / \mathrm{N}$ (Signal/Noise) oranlarını geliştirmiştir. Taguchi tarafından belirlenmiş $\mathrm{S} / \mathrm{N}$ oranları, sistemden istenen hedefe göre seçilmektedir [2332].

Taguchi yöntemi içten yanmalı motorlar üzerine deney yapan araştırmacılar tarafinda da kısmi faktöriyel deney tasarımı olarak kullanılıp, farklı faktör ve seviyelerinin değişik hedefler için optimize edildiği görülmektedir [31,32]. Ayhan ve ark. [23], bir dizel motorunda farklı faktör ve seviyelerin motor performans ve emisyon karakteristiklerini Taguchi yöntemi ile optimize etmişlerdir. Çalışmaları sonucunda deneysel çalışma maliyetlerinde ve zaman kayıplarında \%70'e varan oranda azalma meydana geldiğini vurgulamışlardır. Ansari ve ark. [24] bir dizel motorunda motor performans ve emisyon karakteristikleri açsından optimum faktör ve seviyelerini Taguchi metodunu kullanarak yapmışlardır. $\mathrm{Wu}$ ve $\mathrm{Wu}$ [25] bir dizel motorunda farkl1 oranlarda biyodizel ve $\mathrm{H} 2$ ile birlikte EGR kullanımının motor yanma ve emisyonlara etkisini Taguchi yöntemi ile incelemişlerdir. L9 ortogonal dizisinin kullanıldığı Taguchi deney tasarım yöntemi ile yapılan deneylerde \%67 oranında zaman tasarrufu sağlanabildiğini belirlemişlerdir.

$\mathrm{Bu}$ çalışmada, tek silindirli direkt enjeksiyonlu bir dizel motorunda farklı oranlarda biyodizel-dizel karışımları yakıt olarak kullanılmıştır. Farklı seviyede karışım ile çalışan motorun performans parametreleri, $\mathrm{NO}$ ve is emisyonları açısından en uygun motor yükü ve motor devir sayısının belirlenmesinde Taguchi kısmi faktöriyel deney tasarım ve optimizasyon yöntemi kullanılmıştır.

\section{MATERYAL VE YÖNTEM}

\subsection{Taguchi Yöntemi ile Kısmi Faktöriyel Deney Tasarımı}

Taguchi yöntemi ile deney tasarımı yapılmadan önce faktör ve seviyeleri literatür araştırması yapılarak belirlenmiştir. Her bir faktör 3 seviyeli olacak şekilde belirlenmiştir. Biyodizel-dizel karışım oranı için B0, B20 ve B50 oranları
1. faktörün seviyeleri olarak belirlenmiştir. Motor yükü olarak \%40, \%80 ve \%100 çalışma yükleri 2. Faktör seviyeleri olarak seçilmiştir. 3. Faktör olarak ise motor devri $1200 \mathrm{~d} / \mathrm{d}, 1600 \mathrm{~d} / \mathrm{d}$ ve $2200 \mathrm{~d} / \mathrm{d}$ olarak seçilmiştir. $\mathrm{Bu}$ faktör ve seviyelerin motor döndürme momenti, efektif güç, özgül yakıt sarfiyatı, efektif verim, NO ve İs emisyonları açısından en uygun faktör seviyeleri Taguchi yöntemi ile belirlenmiştir. Çalışmada seçilen faktör ve seviyeleri Tablo 1' de verilmiştir.

Tablo 1. Faktör ve seviyeleri.

\begin{tabular}{|l|l|l|l|}
\hline Faktörler & $\begin{array}{c}\text { Seviye } \\
1\end{array}$ & $\begin{array}{c}\text { Seviye } \\
2\end{array}$ & $\begin{array}{c}\text { Seviye } \\
3\end{array}$ \\
\hline $\begin{array}{l}\text { 1.Faktör; } \\
\text { Biyodizel Oran1,\%, (A) }\end{array}$ & $\mathrm{B} 0$ & $\mathrm{~B} 20$ & $\mathrm{~B} 50$ \\
\hline $\begin{array}{l}\text { 2.Faktör; } \\
\text { Motor Yükü, \%, (B) }\end{array}$ & 40 & 80 & 100 \\
\hline $\begin{array}{l}\text { 3.Faktör; } \\
\text { Motor Devri, d/d, (C) }\end{array}$ & 1200 & 1600 & 2200 \\
\hline
\end{tabular}

Taguchi, yöntemi standart ortogonal dizileri kullanmaktadır. Ortogonal dizler, çok sayıda deneysel durumu açıklamak için oluşturulmuştur. Ortogonal dizi, deneme sırasında bir faktörün seviyelerinin diğer faktörlerin seviyeleri ile eşleştirilmesidir [31]. $\mathrm{Bu}$ çalışmada, 3 faktör 3 seviyeli olarak belirlenmiştir. Belirlenen faktör ve seviyeleri Minitab programına girilmiş, program tarafından L9 ortogonal dizi oluşturulmuştur. L9 olarak ifade edilen ortogonal dizi Tablo 2' de verilmiştir.

Tablo 2. L9 Ortogonal dizisi

\begin{tabular}{|c|c|c|c|}
\hline Deney No & 1.Faktör & 2.Faktör & 3.Faktör \\
\hline 1 & 1 & 1 & 1 \\
\hline 2 & 1 & 2 & 2 \\
\hline 3 & 1 & 3 & 3 \\
\hline 4 & 2 & 1 & 2 \\
\hline 5 & 2 & 2 & 3 \\
\hline 6 & 2 & 3 & 1 \\
\hline 7 & 3 & 1 & 3 \\
\hline 8 & 3 & 2 & 1 \\
\hline 9 & 3 & 3 & 2 \\
\hline
\end{tabular}

Çalışmada motor performans parametresi olarak motor döndürme momenti, efektif güç, özgül yakıt sarfiyatı ve efektif verim seçilmiştir. Emisyon karakteristiği olarak ise $\mathrm{NO}$ ve İs emisyonları incelenmiştir. Ortogonal diziye göre deneyler 3 tekrarlı olarak gerçekleştirilmiş ve gözlem değerlerinin ortalaması alınmıştır. Elde edilen veriler Minatab programına girilerek analizleri yapılmıştır. Taguchi yöntemini tam faktöriyel deney tasarım yöntemlerinden ayıran en önemli özellik performans kriterini Sinyal/Gürültü oranı ile hesaplamasıdır [32]. Buna göre öncelikle döndürme momenti, efektif güç, özgül yakıt 
sarfiyat1, efektif verim, NO ve is emisyonları gözlem değerlerinin $\mathrm{S} / \mathrm{N}$ sonuçlarının hesaplanması için uygun Sinyal/Gürültü oranı formülleri belirlenmiştir. Motor performans parametrelerinden döndürme momenti, efektif güç ve efektif verim için hedef değerin büyük olması istenildiğinden $\mathrm{S} / \mathrm{N}$ oranın hesaplanmasında Taguchi tarafindan önerilen "En Büyük-En İyi" (Larger is better) formülü kullanılmıştır. Özgül yakıt sarfiyatı (ÖYS) ve emisyon karakteristikleri ( $\mathrm{NO}$ ve is emisyonları) için ise hedef değerin küçük olması "En Küçük-En İyi" (Smaller is better) formülü kullanılmıştır. Hesaplamalar için kullanılan $\mathrm{S} / \mathrm{N}$ formülleri aşağıda 1 ve 2 numaralı denklemlerde verilmiştir.

En Büyük-En İyi;

$\mathrm{S} / \mathrm{N}=-10 \log \left[\frac{1}{n} \sum_{i=1}^{n} \frac{1}{y_{i}^{2}}\right]$

En Küçük-En İyi;

$\mathrm{S} / \mathrm{N}=-10 \log \left[\frac{1}{n} \sum_{i=1}^{n} y_{i}^{2}\right]$

$\mathrm{S} / \mathrm{N}$ oranlarına göre her bir performans parametresi ve emisyon sonuçları için Minitab programında analizler yapılmış ve en uygun faktör seviyeleri tespit edilmiştir. Elde edilen sonuçlara göre faktörlerin parametrelere etki düzeylerini belirlemek için varyans analizi (ANOVA) yapılmıştır. Varyans analizi hesaplamalarında kullanılan denklemler (3)-(7) arasında gösterilmiştir:

$\mathrm{SS}_{\mathrm{T}}=\left[\sum_{\mathrm{i}=1}^{\mathrm{N}}(\mathrm{S} / \mathrm{N}) \mathrm{i}^{2}\right]-\frac{\mathrm{T}^{2}}{\mathrm{~N}}$

$\mathrm{SS}_{\mathrm{A}}=\left[\sum_{\mathrm{i}=1}^{\mathrm{K}_{\mathrm{A}}}\left(\frac{\mathrm{A}_{\mathrm{i}}^{2}}{\mathrm{n}_{\mathrm{Ai}}}\right)\right]-\frac{\mathrm{T}^{2}}{\mathrm{~N}}$

$\mathrm{v}_{\text {total }}=\mathrm{N}-1$

$V_{\text {factor }}=\frac{S_{\text {faktor }}}{\vartheta_{\text {factor }}}$

$\mathrm{F}_{\text {factor }}=\frac{\mathrm{V}_{\text {factor }}}{\mathrm{V}_{\text {error }}}$

Burada, $\mathrm{SS}_{\mathrm{T}}$ kareler toplamı, $\mathrm{N}$ toplam deney sayısını, $\mathrm{SS}_{\mathrm{A}}$ A faktörüne bağlı karelerin toplamını, $K_{A}$, A faktörü için seviye sayısını belirtir. $\mathrm{A}_{\mathrm{i}}, \mathrm{A}$ faktörünün toplam seviyelerinin toplamını, $\mathrm{n}_{\mathrm{Ai}}, \mathrm{A}$ faktörünün seviyesinin toplamını ifade eder. $\mathrm{T}$, deneylerin toplam $\mathrm{S} / \mathrm{N}$ oranı değerlerinin toplamını, $\mathrm{V}$ ise serbestlik derecelerini ifade eder. $\mathrm{V}_{\text {factor}}$, faktörün varyansını, $\mathrm{SS}_{\text {factor, faktörün }}$ karelerinin toplamını ve $\mathrm{F}_{\text {factor}}$, faktörün $\mathrm{F}$ oranını belirtir.

Motor performans parametrelerinin hesaplanmasında aşağıdaki denklemler kullanılmıştır.

Motor döndürme momenti ve efektif güç hesaplamalarında;

$M_{d}=F . L$
$\mathrm{P}_{\mathrm{e}}=\frac{2 \pi \cdot F \cdot L \cdot n}{1000} \quad(\mathrm{~kW})$

Burada; $\mathrm{Md}$, döndürme momentini $(\mathrm{Nm}), \mathrm{F}$, fren terazi kuvvetini (N), L, moment kolu uzunluğu (m), $\mathrm{P}_{\mathrm{e}}$, Efektif gücü $(\mathrm{kW}), \mathrm{n}$, ise motor devir sayısını (devir/s) göstermektedir.

Efektif verim, motor milinden alınan işin silindire verilen enerjiye oranıdır ve aşağıdaki formül ile hesaplanmıştır.

$\eta_{e}=\frac{P_{e}}{\dot{m}_{y} \cdot H_{u}}$

Deneylerde yakıt sarfiyatı hacimsel ölçüm yöntemi kullanılarak ölçülmüştür. Özgül yakıt sarfiyatının hesaplanmasında aşağıdaki formül kullanılmıştır.

$\mathrm{b}_{\mathrm{e}}=\frac{3600 \cdot \Delta \mathrm{V} \cdot \rho_{\mathrm{y}}}{\mathrm{P}_{\mathrm{e}} \cdot \Delta \mathrm{t}}=\frac{3600 \cdot \dot{\mathrm{m}}_{\mathrm{y}}}{\mathrm{P}_{\mathrm{e}}}$

Burada, motorun $\Delta \mathrm{V}\left(\mathrm{cm}^{3}\right)$ hacmindeki yakitı $\Delta \mathrm{t}(\mathrm{s})$ zaman aralığında tükettiği dikkate alınarak yakıt debisi (my) hesaplanmaktadır. $\rho_{y}$, yakıtın yoğunluğunu ifade etmektedir [33].

\subsection{Deneysel çalışmalar}

Deneylerde tek silindirli bir dizel motoru hidrolik bir dinamometre ile frenlenmiştir. Deneylerden önce motorun gerekli ayarları katalog değerlerine göre yapılmıştır. Sistematik hataların önüne geçmek için deney düzeneğindeki tüm ölçü aletlerinin kalibrasyonları yapılmıștır. Deneylere başlamadan önce deney motorunun rejim sıcaklığına gelmesi sağlanmıştır. Deneyler esnasında dinamometre tarafından absorbe edilen yük miktarı $\mathrm{S}$ tipi loadcell kullanılarak tespit edilmiştir. Sicaklıkların ölçümünde termokupullar kullanılmıştır. $\mathrm{NO}$ ve is emisyonlarının ölçülmesinde Bosch marka emisyon cihazı kullanılmıştır. Deney motorunun teknik özellikleri Tablo 3' de ve deney düzeneğinin şematik şekli şekil 1' de verilmiştir.

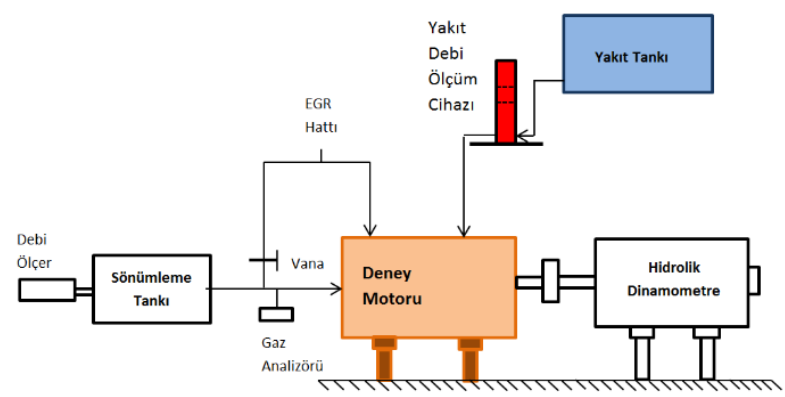

Şekil 1. Deney düzeneği 
Tablo 3. Deney motorunun teknik özellikleri

\begin{tabular}{|l|l|}
\hline Parametre & Değer \\
\hline Motor Tipi & Süper Star \\
\hline Piston Çap1 [mm] & 108 \\
\hline Strok [mm] & 100 \\
\hline Silindir Sayıs1 & 1 \\
\hline Strok Hacmi [dm3] & 0,92 \\
\hline Güç, 2200 d/d, [kW] & 13 \\
\hline Enjektör Açma Basınc1 [bar] & 225 \\
\hline Püskürtme Avans1 [Krank Açıs1] & 29 \\
\hline Sikıştırma Oranı & 17 \\
\hline Maksimum Devir [d/d] & 2500 \\
\hline Soğutma Tipi & Su \\
\hline Püskürtme Tipi & Direkt Enjeksiyon \\
\hline Piston Tipi & Çanak Piston \\
\hline
\end{tabular}

\subsection{Biyodizel Üretimi}

Deneysel çalışmada kullanılan biyodizel transesterifikasyon yöntemi kullanılarak ayçiçek yağından elde edilmiştir. Esterleştirme işleminde alkol olarak metil alkol, katalizör olarak ise potasyum hidroksit kullanılmıştır. Transestefikasyon yöntemi bitkisel veya hayvansal yağlardan biyo yakıt elde edilmesinde en fazla kullanılan yöntemdir[6,14,15]. Esterleştirme işleminde genellikle metil veya etilalkol kullanılmaktadır. Metil alkol kullanılarak elde edilen esterlere metil ester, etil alkol kullanılarak elde edilen esterlere ise etil ester denilmektedir. $\mathrm{Bu}$ çalışmada alkol olarak metil alkol kullanılmıştır. Elde edilen ayçiçek yağı metil esterleri, dizel yakıtı ile farklı oranlarda karıştırılarak çalışmada seçilen bir faktör ve seviyesi belirlenmiştir. Tablo 4' de biyodizel ve dizel yakıtının özellikleri verilmiştir.

Tablo 4. Dizel ve biyodizel yakıtların özellikleri

\begin{tabular}{lcc}
\hline \multicolumn{1}{c}{ Yakıt Özellikleri } & Biyodizel & Dizel \\
\hline Kapalı formül & $\mathrm{C}_{19} \mathrm{H}_{35,2} \mathrm{O}_{2}$ & $\mathrm{C}_{12,226} \mathrm{H}_{23,2950}$ \\
Molekül ağırlığı $(\mathrm{g} / \mathrm{mol})$ & 296 & $120-320$ \\
Özgül ağırlığı $(\mathrm{kg} / \mathrm{dm} 3)$ & $0,87-0,88$ & $0,82-0,86$ \\
Kinematik viskozite $(\mathrm{mm} 2 / \mathrm{s})$ & 4,3 & $2,5-3,5$ \\
Setan sayıs1 & $>55$ & $49-55$ \\
Alevlenme noktası $\left({ }^{\circ} \mathrm{C}\right)$ & $>100$ & $>55$ \\
Alt 1s1l değeri $(\mathrm{kJ} / \mathrm{kg})$ & 39576 & 42640 \\
\hline
\end{tabular}

\section{ARASTIRMA BULGULARI}

\subsection{Motor performans parametreleri}

Farklı biyodizel oranları, motor devirleri ve motor yükleri için yapılan deneysel çalışmada motor performans ve egzoz emisyon üzerine etkileri Taguchi istatistiksel deney tasarım yöntemi kullanılarak incelenmiştir.

Şekil 2'de motor efektif gücüne etki eden faktör ve seviyelerinin değişimleri görülmektedir. Efektif gücün optimum değeri 2200 d/d'da, B20 biyodizel karışımında ve \%100 yük durumunda elde edilmiştir. En iyi kombinasyon A2B3C3'dir.

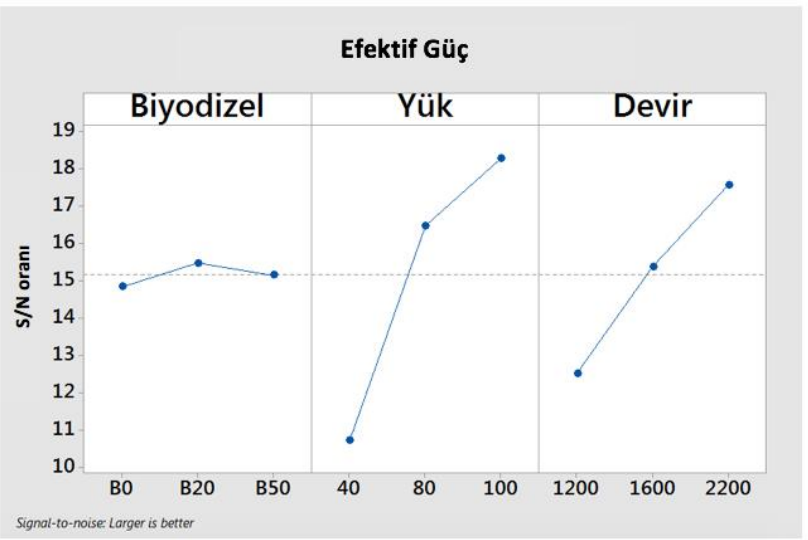

Şekil 2. Efektif güç için faktör seviyeleri $\mathrm{S} / \mathrm{N}$ değerleri

Şekil 3'de motor torkuna etki eden faktör ve seviyelerinin değişimleri görülmektedir. Motor torkunun optimum değeri 1600 d/d'da, B20 biyodizel karışımında ve \%100 yük durumunda elde edilmiştir. En iyi kombinasyon A2B3C2'dir.

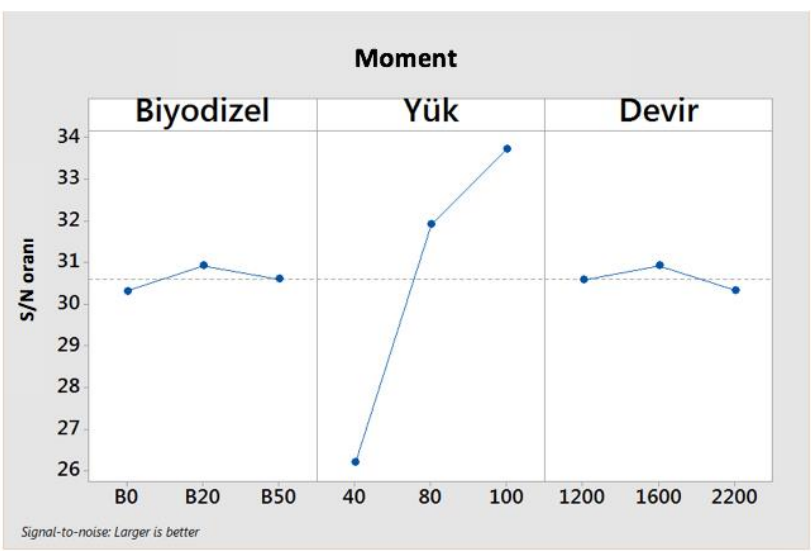

Şekil 3. Motor torku için faktör seviyeleri S/N değerleri

Deneysel çalışmalar sonucunda motorda farklı oranlarda biyodizel kullanıldığında standart motora göre, efektif gücün ve torkun arttığı görülmektedir. Efektif gücün B20 yakıtına kadar artması ve B20 yakıtında en iyi seviyeye ulaşmasının Biyodizelin içerdiği oksijen miktarı ile ilgili olduğu düşünülmektedir. Yakıttaki oksijen miktarının fazla olması yanmanın iyileşmesini sağlamaktadır. $\mathrm{Bu}$ durum momentin ve dolayısıyla efektif gücün artmasına sebep olmaktadır. Yakıt içerisindeki biyodizel oranının \%20'den fazla olduğu durumda biyodizelin alt 1sıl değerinin dizel yakıttan düşük olması sebebiyle 1 sı girdisinin daha az olması döndürme momentini ve efektif gücü azaltmaktadır. Motor karakteristik eğrilerinden de bilindiği üzere genel olarak atmosferik motorlarda momentin en yüksek olduğu devir orta bir devirdir. Deney motorunda en yüksek moment $1600 \mathrm{~d} / \mathrm{d}$ 'da elde edilmiştir. Bu devirden sonra devir arttıkça moment azalır. Bunun nedeni silindire girecek karışım miktarının azalması, motorun hacimsel 
veriminin düşmesi ve artan sürtünme kayıplarıdır. Efektif güç ise momente bağlı olduğu gibi motor devrine de bağlıdır. Devir arttıkça çevrim sayısındaki artmaya bağlı olarak efektif güç artmaktadır.

Şekil 4'te motor özgül yakıt sarfiyatına (ÖYS) etki eden faktör ve seviyelerinin değişimleri görülmektedir. Özgül yakıt sarfiyatının optimum değeri, $1600 \mathrm{~d} / \mathrm{d}$ 'da, B20 biyodizel karışımında ve $\% 80$ yük durumunda elde edilmiştir. En iyi kombinasyon A2B2C2'dir.

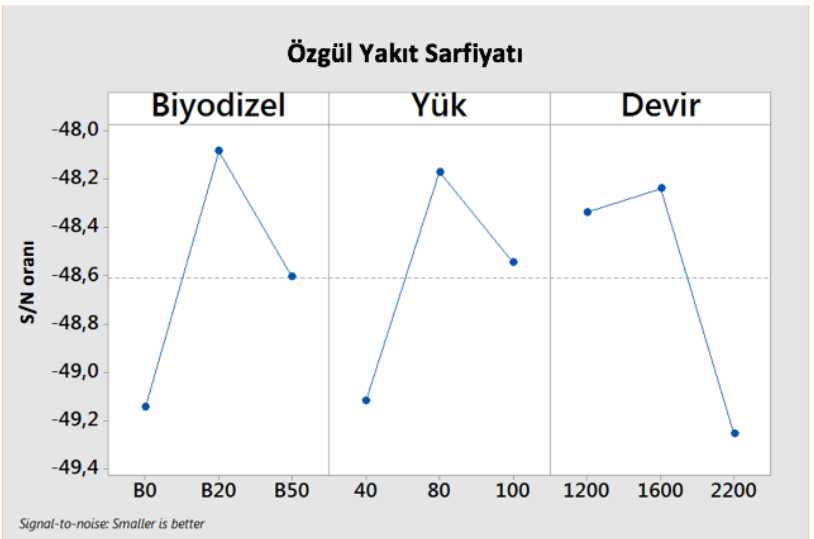

Şekil 4. ÖYS için faktör seviyeleri S/N değerleri
Şekil 5'te efektif verime etki eden faktör ve seviyelerinin değişimleri görülmektedir. Efektif verimin optimum değeri, $1600 \mathrm{~d} / \mathrm{d}$ 'da, B20 biyodizel karışımında ve \%80 yük durumunda elde edilmiştir. En iyi kombinasyon A2B2C2'dir.

Motor performans parametreleri için varyans analizi sonuçları Tablo 5'te verilmiştir. $\mathrm{Bu}$ sonuçlara göre faktörlerin efektif güç, motor torku, özgül yakıt sarfiyatı ve efektif verimde $\% 95$ ile \%99,99 aralığında etkili oldukları tespit edilmiştir.

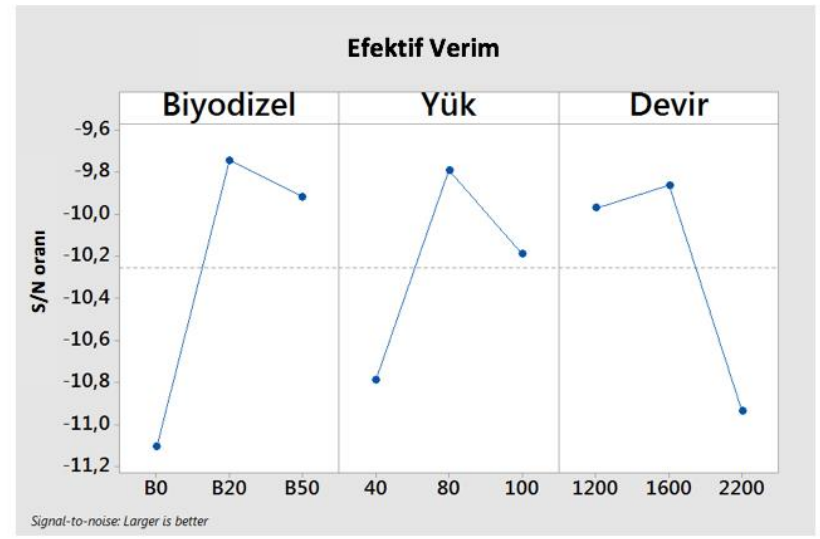

Şekil 5. Efektif verim için faktör seviyeleri S/N değerleri

Tablo 5. Motor performans parametreleri için varyans analizi sonuçları.

\begin{tabular}{|c|c|c|c|c|c|}
\hline & Faktörler & $\begin{array}{c}\text { Serbestlik } \\
\text { Derecesi }\end{array}$ & $\begin{array}{c}\text { Kareler Toplamı, } \\
\text { SS }\end{array}$ & $\begin{array}{c}\text { Kareler Ortalaması, } \\
\text { V }\end{array}$ & Fteori \\
\hline \multirow{5}{*}{ Moment } & A-Biyodizel & 2 & 0,033 & 0,0166 & 1,02 \\
\hline & B - Yük & 2 & 101,906 & 50,9529 & $3124,69 * * *$ \\
\hline & C-Devir & 2 & 0,675 & 0,3373 & $20,69 *$ \\
\hline & Hata & 2 & 0,033 & 0,0163 & \\
\hline & Toplam & 8 & 102,646 & & \\
\hline \multirow{5}{*}{ Efektif Güç } & A-Biyodizel & 2 & 0,028 & 0,0138 & 0,62 \\
\hline & B - Yük & 2 & 103,249 & 51,6246 & $2327,96 * * *$ \\
\hline & C-Devir & 2 & 34,996 & 17,4979 & $789,05^{* *}$ \\
\hline & Hata & 2 & 0,044 & 0,0222 & \\
\hline & Toplam & 8 & 138,317 & & \\
\hline \multirow{5}{*}{ Efektif Verim } & A-Biyodizel & 2 & 1,12227 & 0,56114 & $26,04 *$ \\
\hline & B - Yük & 2 & 2,90409 & 1,45205 & $67,39 *$ \\
\hline & $\mathrm{C}-$ Devir & 2 & 2,82313 & 1,41157 & $65,51 *$ \\
\hline & Hata & 2 & 0,04309 & 0,02155 & \\
\hline & Toplam & 8 & 6,89259 & & \\
\hline \multirow{5}{*}{ ÖYS } & A-Biyodizel & 2 & 0,34723 & 0,17362 & 8,8 \\
\hline & B - Yük & 2 & 2,5967 & 1,29835 & $65,82 *$ \\
\hline & $\mathrm{C}-$ Devir & 2 & 2,52186 & 1,26093 & $63,92 *$ \\
\hline & Hata & 2 & 0,03945 & 0,01973 & \\
\hline & Toplam & 8 & 5,50524 & & \\
\hline
\end{tabular}

* \%95 etki, **\%99 etki, ***\%99.99 etki

\subsection{Emisyon karakteristikleri}

Şekil 6'da NO emisyonuna etki eden faktör ve seviyelerinin değişimleri görülmektedir. NO emisyonunun optimum değeri \%40 yük değerinde, 2200 d/d' ve B20 biyodizel karışımında elde edilmiştir. En iyi kombinasyon A2B1C3'dir.

Yakıt olarak biyodizel kullanılması ile NO emisyonları ise artmıştır. NO miktarının artmasının sebebi biyodizel 
yakıtının oksijen içeriğinin dizele göre daha yüksek olması nedeniyle yanma veriminin artmasıdır. Yanma verimin iyileşmesi adyabatik alev sıcaklığını yükseltmektedir. Bu nedenle artan sıcaklıklar NO emisyonlarını arttırmıştır.

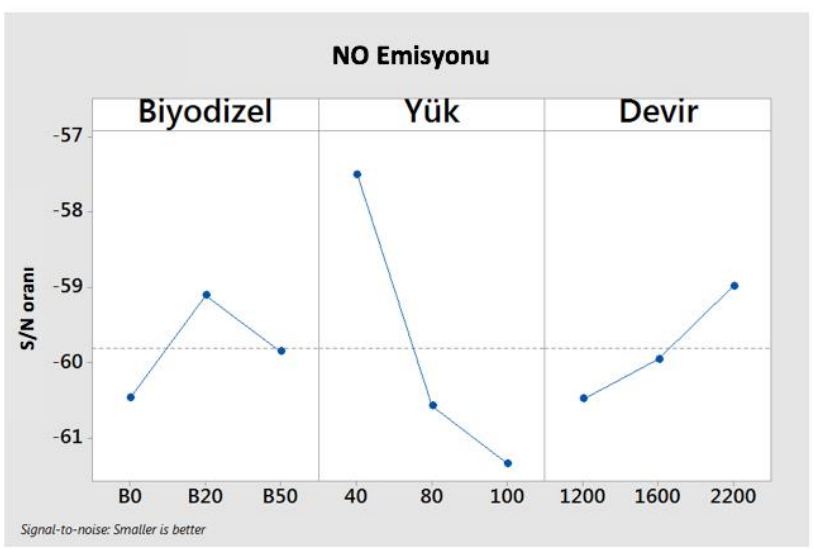

Şekil 6. NO emisyonu için faktör seviyeleri S/N değerleri

Şekil 7'de is emisyonuna etki eden faktör ve seviyelerinin değişimleri görülmektedir. İs emisyonunun optimum değeri \%40 yük değerinde, $1200 \mathrm{~d} / \mathrm{d}$ ve B50 biyodizel karışımında elde edilmiştir. En iyi kombinasyon A3B1C1'dir.

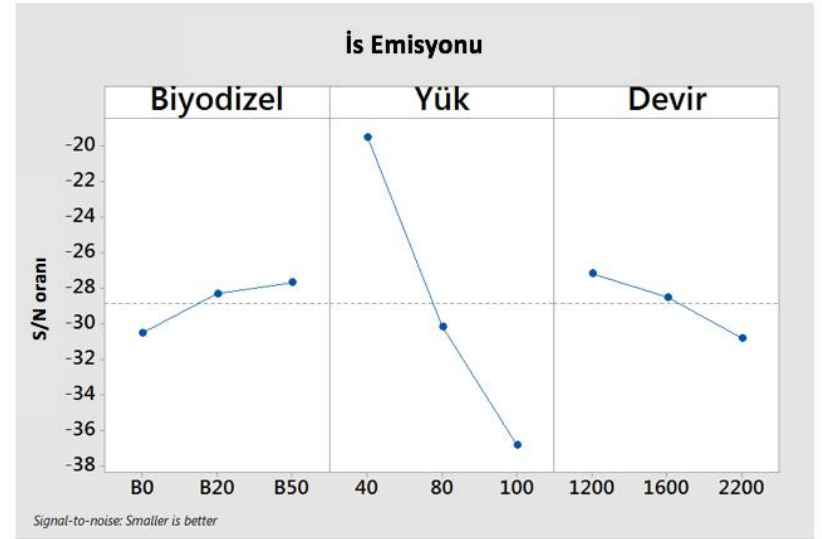

Şekil 7. İs emisyonu için faktör seviyeleri S/N değerleri

İs emisyonlarının azalmasının sebebi, biyodizel yakıtının oksijen içeriğinin fazla olması nedeniyle hava fazlalık katsayısınun artmasına neden olmaktadır. Hava fazlalık katsayısınun değişimi emisyonların değişimini etkileyen en önemli parametredir.

Emisyon karakteristikleri için varyans analizi sonuçları Tablo 6'da verilmiştir. Bu sonuçlara göre faktörlerin egzoz emisyonlarında \%95 ile \%99,99 aralığında etkili oldukları tespit edilmiştir.

Tablo 6. Emisyon karakteristikleri için varyans analizi sonuçları.

\begin{tabular}{|c|c|c|c|c|c|}
\hline & Faktörler & $\begin{array}{c}\text { Serbestlik } \\
\text { Derecesi }\end{array}$ & $\begin{array}{c}\text { Kareler Toplamı, } \\
\text { SS }\end{array}$ & $\begin{array}{c}\text { Kareler Ortalaması, } \\
\text { V }\end{array}$ & Fteori \\
\hline \multirow{4}{*}{ NO Emisyonu } & A - Biyodizel & 2 & 1,596 & 0,7979 & 1,09 \\
\cline { 2 - 6 } & B - Yük & 2 & 22,303 & 11,1515 & 15,22 \\
\cline { 2 - 6 } & C - Devir & 2 & 10,307 & 5,1537 & 7,03 \\
\cline { 2 - 6 } & Hata & 2 & 1,466 & 0,7328 & \\
\cline { 2 - 6 } & Toplam & 8 & 35,672 & & 0,39 \\
\hline \multirow{4}{*}{ İs Emisyonu } & A - Biyodizel & 2 & 13,15 & 6,577 & 13,55 \\
\cline { 2 - 6 } & B - Yük & 2 & 458,65 & 229,324 & 0,59 \\
\cline { 2 - 6 } & C - Devir & 2 & 20,13 & 10,063 & \\
\cline { 2 - 6 } & Hata & 2 & 33,84 & 16,921 & \\
\cline { 2 - 6 } & Toplam & 8 & 525,77 & & \\
\hline
\end{tabular}

*\%95 etki, **\%99 etki, ***\%99.99 etki.

\section{GENEL DEĞERLENDİRME}

$\mathrm{Bu}$ çalışmada, Taguchi deney tasarım yöntemi kullanılarak, farklı yük ve devirlerde çalışan bir dizel motorunda farklı biyodizel uygulanmasının motor performans parametreleri, $\mathrm{NO}$ ve is emisyonlardaki değişimler incelenmiştir. Yapılan incelemeler sonucunda motor yükünün, motor devrinin, farklı biyodizel-dizel karışımlarının motor performans parametreleri ve NO-is emisyonları üzerinde etkili olduğu tespit edilmiştir. Genel olarak elde edilen sonuçlar aşağıdaki gibidir;

-Efektif güç için en iyi sonuçlar, B20 yakıtında, \%100 yük ve $2200 \mathrm{~d} / \mathrm{d}$ 'da elde edilmiştir. En iyi kombinasyon A2B3C3'dir.
-Motor torku için en iyi sonuçlar; B20 yakıtında, \%100 yük ve $1600 \mathrm{~d} / \mathrm{d}$ 'da elde edilmiştir. En iyi kombinasyon A2B3C2'dir.

-Özgül yakıt sarfiyatı (ÖYS) için optimum sonuçlar; B20 yakıtında, \%80 yük ve 1600 d/d'da elde edilmiştir. En iyi kombinasyon A2B2C2'dir.

-Efektif verim için en iyi sonuçlar; B20 yakıtında, \%80 yük $1600 \mathrm{~d} / \mathrm{d}$ 'da elde edilmiştir. En iyi kombinasyon A2B2C2'dir.

-NOx emisyonları açısından en iyi sonuçlar; B20 yakıtta, $\% 40 \mathrm{k}$ ısmi yük ve $2200 \mathrm{~d} / \mathrm{d}$ 'da tespit edilmiştir. En iyi kombinasyon A2B1C3'dir. 
-İs emisyonları için en iyi sonuçlar; B50 yakıtta, \%40 kısmi yük ve $1200 \mathrm{~d} / \mathrm{d}$ 'da tespit edilmiştir. En iyi kombinasyon A3B1C1'dir.

Sonuç olarak motor performans parametreleri açısından optimum sonuç B20 yakıtı, \%100 yük konumu ve $1600 \mathrm{~d} / \mathrm{d}$ olarak belirlenmiştir. Ayrıca NOx ve is emisyonları açısından optimum değer B20 yakıtı, \%40 yük ve 2200 d/d olarak tespit edilmiştir.

Ayrıca Taguchi istatistiksel deney tasarım yönteminin kullanılması ile 16 deney 3 tekrarlı yapilarak zaman ve maliyet açısından tasarruf sağlanmıştır. Yapılan deneyler \%95 ile \%99,99 güven aralığında gerçekleştirilmiştir.

\section{KAYNAKÇA}

[1] K.A. Abed, M.S. Gad, A.K. El Morsi, M.M. Sayed and S.A. Elyazeed, "Effect of biodiesel fuels on diesel engine emissions," Egyptian Journal of Petroleum, Journal Homepage, 2019.

[2] Ertan ALPTEKIN, Mustafa ÇANAKÇI, Biyodizel ve Türkiye'deki durumu, Mühendis ve makine, Cilt: 47 Sayı: 561,2003.

[3] J.Suryawanshi, N.Deshpande, "Overview of EGR, injection timing and pressure on emissions and performance of CI engine with pongamia methyl ester", SAE Techincal Paper, 2005.

[4] M.B.Sirman, E.C.Owens, K.A.Whitney, "Emissions comparison of alternative fuels in an advanced automotive diesel engine", SAE Technical Paper, 2000.

[5] Yücesu, H.S., Altın, R., Çetinkaya, S., "Dizel Motorlarında alternatif yakıt olarak bitkisel yağ kullanımının deneysel incelenmesi", Turkish Journal of Engineerıng and Environmental Sciences, vol. 25, pp. 3949, 2001.

[6] A. Parlak, H. Karabaş, İ. Özsert, V. Ayhan and İ. Cesur, "Application of Taguchi's methods to investigate factors affecting emissions of a diesel engine running with tobacco oil seed methyl ester," Int. J. Vehicle Design, Vol. 59, Nos. 2/3, 2012.

[7] A. Keskin ve K. Ekşi, "Dizel motorlarda mısır yağı biyodizelinin yakıt olarak kullanımının motor performans ve emisyonuna etkisi," C.B.Ü. Fen Bilimleri Dergisi, 2.1 (2006) 49-55.

[8] C. Haşimoğlu, "Düşük 1S1 kayıplı bir dizel motorunda biyodizel kullanımının performans ve emisyon parametrelerine etkisi," Doktora Tezi, Sakarya Üniversitesi Fen Bilimleri Enstitüsü, Sakarya, 2005.

[9] A.Parlak, V.Ayhan, İ.Cesur, G.Kökkülünk, "Investigation of the effects of steam injection on performance and emissions of a diesel engine fuelled with tobacco seed oil methyl ester", Fuel Processing Technology, vol. 116, pp. 101-109, 2015.

[10] A.K.Agarwal, L.Das, "Biodiesel development and characterization for use as a fuel in compression ignition engines", Journal of Enginering Gas Turbines Power, vol. 123, pp. 123:440-447, 2007.
[11] C.A.Sharp, T.W.Ryan, G.Knothe, "Heavy-duty diesel engine emissions tests using special biodiesel fuels", SAE Technical Paper, 2005.

[12] J.Suryawanshi, N.Deshpande, "Overview of EGR, injection timing and pressure on emissions and performance of CI engine with pongamia methyl ester", SAE Techincal Paper, 2005.

[13] M.B.Sirman, E.C.Owens, K.A.Whitney, "Emissions comparison of alternative fuels in an advanced automotive diesel engine", SAE Technical Paper, 2000.

[14] Ayhan. V., Tunca S., Cesur İ., Özsert İ., Ergen G., Ayçiçek Yağı Metil Ester Karışımlarının DI Bir Dizel Motorunun Performans ve Emisyonlarına Etkisi, Academic Platform Journal of Engineering \& Science APJES, 7-1, 6773, 2019.

[15] İ.Cesur, V.Ayhan,P.Parlak, "Bir Dizel Motorunda Tavuk Yağı Metil Esteri Kullanılmasının Performans Ve Emisyonlara Etkisi", 10. Uluslararası Yanma Sempozyumu, Sakarya/ Türkiye, 09-10 Ekim 2008.

[16]Yılmaz E., \%10 Balık Yağı Biyodizeli-\%90 Dizel Yakıt Karışımı İle Çalışan Direkt Enjeksiyonlu Bir Dizel Motorunda Yanma ve Performans Karakteristiklerinin İncelenmesi, Gazi Üniversitesi Fen Bilimleri Dergisi Part C Tasarım ve Teknoloji 7(1):12-24, Mart 2019, DOI: $10.29109 /$ gujsc.466544.

[17]Uyumaz, A., Boz, F., Baydır, Ş.A., Direkt Enjeksıyonlu Bır Dızel Motorunda Atık Zeytınyağı Bıyodızelının Yanma, Performans Ve Emisyon Karakterıstıklerı, Gazi Üniversitesi Fen Bilimleri Dergisi Part C: Tasarım ve Teknoloji, 2018, https://doi.org/10.29109/http-gujsc-gaziedu-tr.317409.

[18]Sarıdemir, S., Biyodizel-Dizel Yakıt Karışımlarının Motor Gürültü Ve Egzoz Emisyonlarına Olan Etkisi, 4th International Symposium on Innovative Technologies in Engineering and Science 3-5 November 2016 (ISITES2016 Alanya/Antalya - Turkey).

[19] N. Usta, Ö. Can ve E. Özgtürk, "Alternatif dizel motor yakıtı olarak biyodizel ve etanolün karşılaştırılması," Pamukkale Üniversitesi Mühendislik Fakültesi, Mühendislik Bilimleri Dergisi Sayı:3, Denizli, 2005.

[20] Z.Ö. Özdemir ve H. Mutlubaş, "Biyodizel üretim yöntemleri ve çevresel etkileri," Kırklareli University Journal of Engineering and Science 2 (2016) 129-143.

[21] M.E. Tat, "Investigation of oxides of nitrogen emissions from biodiesel-fueled engine," $\mathrm{Ph}$. D. Iowa State University, 41, 2003.

[22] S. Manigandan, P. Gunasekar, J. Devipriya and S. Nithya, "Emission and 1njection characteristics of corn biodiesel blends in diesel engine," Fuel, 235 (2019) 723735.

[23] V. Ayhan, İ. Özsert, Y. Çay, A. Çoban ve İ. Cesur, "DI bir dizel motorunda optimum buhar püskürtme oranı ve yakıt püskürtme zamanının taguchi metodu ile deneysel olarak belirlenmesi," Journal of New Results in Engineering and Natural Science, No:8 (2018) 128-136.

[24] N.A. Ansari, A. Sharma and Y. Singh, "Performance and emission analysis of a diesel engine implementing polanga biodiesel and optimization using Taguchi method," 
Process Safety and Environmental Protection, 120 (2018) $146-154$.

[25] $\mathrm{H}$. Wu and $\mathrm{Z}$. Wu, "Using Taguchi method on combustion performance of a diesel engine with diesel/biodiesel blend and port-inducting H2," Applied Energy 104 (2013) 362-370.

[26] D.H. Lee, J.S. Park, M.R. Ryu and J.H. Park, "Development of a highly efficient low-emission diesel engine-powered co-generation system and its optimization using Taguchi method," Applied Thermal Engineering 50 (2013) 491-495.

[27] M. Balkı, C. Sayın and M. Sarıkaya, "Optimization of the operating parameters based on Taguchi method in an s1 engine used pure gasoline," Ethanol And Methanol, Fuel 180 (2016) 630-637.

[28] T. Ganapathy, K. Murugesan and R.P. Gakkhar, "Performance optimization of jatropha biodiesel engine model using Taguchi approach," Applied Energy 86
(2009) 2476-2486.

[29] Ç. Sarpkaya, "Taguchi metoduna dayalı gri ilişkiler analizi ile haşıl prosesinin optimizasyonu," Doktora Tezi, Çukurova Üniversitesi Fen Bilimleri Enstitüsü, Adana, 2014.

[30] Z.Y. Wu, H.W. Wu and C.H. Hung, "Applying Taguchi method to combustion characteristics and optimal factors determination in diesel/biodiesel engines with portinjecting LPG," Fuel 117 (2014) 8-14.

[31] S. İzgiz, "Deney tasarımı ve Taguchi metodu-ürün ve proseslerin optimizasyonu, Kocaeli, 1999.

[32] M. Şirvanc1, Kalite için deney tasarımı, Literatür Yayınları, 1. Basım, İstanbul, 1997.

[33] Ayhan, V., Bir Dizel Motoruna Buhar Enjeksiyonunun NOx ve İs Emisyonlarına Etkisinin Araştırılması. Sakarya Üniversitesi Fen Bilimleri Enstitüsü, 2009, Doktora Tezi, Sakarya. 